\title{
Departing words from the editor
}

Howard Bauchner, Editor-in-Chief

\section{My final Atoms}

And with this Atoms, after 8 years as editor, I say good-bye. On 1 July 2011, I will become Editor in Chief of the Journal of the American Medical Association. During this time I have written 95 Atoms (Martin Ward-Platt penned one while I was unavailable). I have learned many things over the past 8 years, the journal has changed, and I have many thanks to give.

\section{What have I learned?}

Two cover pictures are unacceptable- a young child with asthma using an inhaler, but without a spacer, and an infant being fed by bottle, rather than at breast.

Plagiarism, duplicate publication, conflict of interest, falsification and fabrication were all vague concepts before I became editor. That changed quickly. Authors continue to amaze me - a publication in two different journals, in which $75 \%$ of the text is the same, the tables are identical, but the authors claim that the research question is different.

Conflict of interest remains a persistent concern. Sometimes authors do not declare speaking fees or industry support for a foundation they represent. They either do not recognise or do not believe that these relationships represent a conflict of interest and must be declared.

Plagiarism is becoming a more common problem. Many journals, including $A D C$, have recently added software to detect similarities between papers. I once again remind authors if you are not sure, either use quotation marks, or carefully reference phrases taken from the work of others.

\section{$A D C$ is a world class journal}

The intellectual capacity and integrity of our authors and editors is world class. What a privilege it has been to read virtually every single submission during my tenure - by my quick estimation 6000 papers - including original research papers, casereports, reviews, editorials, perspectives and Archimedes. I have attended approximately 100 auctions since I became editor and participated in many robust discussions about each and every paper that we considered for publication. We discussed, disagreed, debated and joked. But all of us left those meetings better informed.

How has the journal changed?

We have aggressively pursued intelligent innovation. Journals that do not evolve will not thrive. Articles are shorter - we have listened to our readers. The long, rambling introductions and discussions are gone. The original research reports reflect the vast research enterprise. Randomised clinical trials, qualitative studies, diagnostic reports, decision analyses and audits are now included in our research pages. We have paid particular attention to our value-added material. Guideline reviews, Archimedes, perspectives, editorials and papers about global health fill our pages. I am especially proud of our original research papers and the debut and maturation of Education and Practice (E\&P). Our readers have repeatedly told us that E\&P is a great read, and want more of it.

$A D C$ is in excellent shape. Circulation has increased $35 \%$, submissions are up $75 \%$, the impact factor has nearly doubled, and most importantly you - our readers like our journal. Our readership surveys have guided change and content, and it has been gratifying that the number of readers who indicate that the journal is very good and/or excellent has increased substantially since 2003. When I first become editor, colleagues asked me what I hoped to accomplish. First and foremost I wanted $A D C$ to be a good read - a modern journal that included many various article types and experimented with different ways of communicating. I fully recognise that not every original research report, review, editorial, perspective or column will appeal to every reader, but my goal has been to ensure that when you get your $A D C$ each month, there are five or six papers you find appealing. Certainly we are a conduit for scientific reports, and the ultimate goal is to improve the lives of children, but my vision was far more modest.

\section{Many thanks}

The list of people to thank is long. So I will restrict it to those who have been with me for most of my tenure. First and foremost is the previous editor, Harvey Marcovitch - a wise and caring friend. Although he occasionally points out that Americans are a bit too emotional, he does allow me a good hug hello now and again. He has always been available to help, guide and offer counsel when asked, but has never interfered. I make the same pledge to the next editor. I have dealt with three College Presidents, Alan Craft, Pat Hamilton, Terence Stephenson and Graham Sleight has been the long-time college representative in matters related to the journal. The College has never interfered with anything we have published and have afforded me complete editorial independence.

Some of the editors deserve particular mention. Martin Ward Platt and Ben Stenson have led Fetal and Neonatal since 2003. They have made it the pre-eminent journal in this field. Their steady hand, sharp eye for papers and leadership, has allowed me to concentrate on other issues. Patrick Cartlidge (Reviews), Tim Cole (Statistics), Ieuan Hughes (Editorials), Bob Phillips (Archimedes), Ian Wacogne (E\&P), Nick Brown (Global Health), Robert Scott-Jupp (Book Reviews and Images) and Imti Choonara (Drug Therapy) deserve special thanks.

The guidance I have received from the BMJ folks has been very important. Alex Williamson and Peter Ashman, the two publishing directors have been wonderful to work with. Jane Smith has always been available for a quick consultation. Richard Smith and Fi Godlee - the two last Editors of $B M J$ - are important role models and colleagues.

The many editorial assistants I have worked with over the years have been exceptional. They are the face of the journal to authors, deal with my many eccentricities and deserve many thanks. Malcolm Smith helps me each month to 'assemble' ADC - thank you.

Most importantly I thank Janet O'Flaherty the publisher. I have known Janet for close to 15 years. She has been available nights and weekends and helped with every decision, every change and answered every query. She has been far more than a publisher; she has been my partner in whatever success I can claim.

It has been an honour and privilege to steer $A D C$ for the past 8 years. Journals are sacred trusts. It was a remarkable decision for the RCPCH and BMJ Publishing to place their faith in me. I cannot possibly thank either of them enough. The editors have worked tirelessly to make $A D C$ a better journal, a world-class publication that critiques and informs. Lastly, of course, I must thank you our readers both in the UK and around the world you allow us to enter your homes each month by print or electronically, and give us some of your valuable time to scan our journal and read some of its content. 